\title{
Aplicativo The Maze: a word hunt - uma ferramenta à prática do léxico e fonética de inglês mediada por recursos semióticos
}

\author{
Enio Luiz Costa Tavares, IFSertãoPE, enio.tavares@ifsertao-pe.edu.br \\ https://orcid.org/0000-0003-3275-4205 \\ Alan Laurentino Dias, IECOM, alan.dias.pe@gmail.com \\ https://orcid.org/0000-0002-8498-3643 \\ Renata Fonseca Lima da Fonte, Unicap, renata.fonte@unicap.br \\ https://orcid.org/0000-0002-3407-4409 \\ Francisco Madeiro Bernardino Junior, Unicap, francisco.madeiro@ unicap.br \\ https://orcid.org/0000-0002-6123-0390
}

\begin{abstract}
Resumo: Neste artigo são analisados recursos semióticos (RS) que intensificam o interesse, a motivação e o engajamento da aprendizagem de inglês. Duas versões com diferentes semioses compunham o aplicativo nominado The Maze: a word hunt: a) considerando os RS em conformidade com a Análise Composicional (AC) da imagem na Gramática do Design Visual (GDV); b) não levando em consideração os RS em conformidade com a AC da imagem na GDV. Os sujeitos participaram de um teste de preferência e, ao final, apontaram como RS intensificadores: sons, elementos de gamificação, disposição espacial, valores informativos, transcrições fonéticas, entre outros. Os resultados revelam que os RS incorporados ao Aplicativo The Maze contribuem à aprendizagem do léxico e da fonética da língua inglesa.
\end{abstract}

Palavras-chave: aplicativo pedagógico; ensino de inglês; recursos semióticos; semiótica

\section{The Maze: a word hunt application - a tool for English lexicon and phonetic practice mediated by semiotic resources}

\begin{abstract}
In this research semiotic resources (SR) which intensify the interest, motivation and engagement in English learning are analysed. Two versions with different semioses made up the application named The Maze: a word hunt: a) considering the SR complying with the Compositional Analysis (CA) of image in The Grammar of Visual Design (GVD); b) not taking into account the SR complying with the CA in The GVD. The subjects took part of a preference test and, at the end, pointed out as intensifying SR: sound, elements of gamification, spatial arrangement, information values, phonetic transcription, among others. The results show that the SR incorporeted to the Application The Maze contribute to the lexicon and phonetic learning of English.
\end{abstract}

Keywords: pedagogical application; English teaching; semiotic resources; semiotics

\section{Introdução}

Ao longo das duas últimas décadas, especialistas da educação têm se esforçado para comprovar a importância do uso de imagens, sejam inertes ou em movimento, para promover consciência (inter)cultural, social e gerar sentido (Herrero et al., 2019)(Donaghy, 2017)(Goldstein, 2016).

Fala-se sobre o Letramento Visual diante da necessidade de as pessoas saberem "ler paisagens, expressões, figuras, fotos, interfaces, desenhos, gráficos e tudo que se refere às construções visuais" (Goldstein, 2016, p. 4). Segundo Grundlingh (2017, p.8), 
os conteúdos não verbais, que compõem as imagens, "colaboram na construção de intenções do falante em processos de comunicação e significação".

As tecnologias digitais favorecem o uso de recursos semióticos: cores, ângulos, imagens, figuras, fotos, sons, luzes, tons, palavras, fontes, setas, linhas, arcos, os quais comunicam-se em interfaces por meio de valores gerados entre suas relações (Von Wangenhein et al., 2020). De acordo com Hodge e Kress (2014) e Bezemer e Kress (2016), os recursos semióticos que compõem as imagens auxiliam na criação de sentidos em atos comunicativos e em processos de (re)ssignificação.

Hodge e Kress (2014) tomam por base a Semiótica Social e consideram recursos semióticos todos e quaisquer meios que favoreçam a concretização das ações do signo, ou seja, suas semioses, como meios para significados sociais. Segundo Kress (2010), o homem é um criador de signos, sendo estes algo com o potencial de representar alguma coisa, sem ser essa coisa, mas tem o poder de representá-la. Dependendo da construção social, valores, experiências sociais, cultura, entre outros fatores, o signo pode ser arbitrário.

Vislumbrou-se a necessidade de analisar e propor melhorias quanto à linguagem dos aplicativos pedagógicos voltados ao ensino de inglês sob a perspectiva da Análise Composicional (AC) acerca da imagem, de acordo com a Gramática do Design Visual (GDV), proposta por Kress e Van Leeuwen (2006).

Observam-se estudos em Traxler (2020), Macena et al. (2020), Donaghy (2017), Araújo et al. (2019), Sousa e Pinheiro (2019) que transpassam modos imagéticos em movimento: jogos, aplicativos pedagógicos, filmes, animações em ambientes virtuais de aprendizagem (AVAs), ferramentas para gamificação entre tantas outras possibilidades à luz da Semiótica. Outros estudos têm o foco em imagens inertes, como em Zhang e O’Halloran (2019), Lim e Phua (2019), Caiado et al. (2018), Wigham e Satar (2016), Danielsson e Selander (2016), Santaella e Nöth (2015) e Grigoletto et al (2011). Pontuase uma lacuna existente à AC das interfaces de um jogo de simulações à luz da GDV.

Esta pesquisa teve como objetivo analisar recursos semióticos que intensificam o interesse, a motivação e o engajamento da aprendizagem de inglês por meio de um aplicativo pedagógico usado em dispositivos móveis de tela reduzida. No estudo, procurou-se responder ao problema: como a AC, com base na GDV, ajuda-nos a identificar recursos semióticos intensificadores do interesse, motivação e engajamento na aprendizagem de inglês por meio de aplicativos?

O aplicativo The Maze: a word hunt foi idealizado para favorecer a prática do campo lexical e da fonética. O aplicativo se classifica como um jogo em Realidade Virtual (RV) com uso de gamificação.

Neste artigo, relatam-se a ferramenta desenvolvida para o estudo, os materiais e métodos utilizados para levantar os dados, os quais são discutidos e analisados.

Apresenta-se como contribuição um produto tecnológico decorrente da pesquisa, um novo aplicativo, com uso de realidade virtual, para o apoio ao ensino de Inglês.

\section{A teoria que fundamenta a análise do aplicativo: semiótica social}

A Semiótica Social (SS) toma a iconografia como fulcro ao seu estudo e análise de estruturas simbólicas (Tavares, 2020). A SS analisa as possibilidades de relações a partir das influências do meio, indivíduos, acontecimentos, cultura e o imagético. Observa-se que é bastante influenciada pela Gramática Sistêmico-Funcional (GSF) de Halliday e Matthiessen (2004).

De acordo com Santos (2014, p. 165 - 166), a proposta da GSF originou-se nas décadas de 1960 e 1970. De característica funcionalista, considera a gramática em termos de como ela é usada para produzir significados, uma vez que concebe a língua 
como uma "rede de sistemas interligados que o falante faz uso (base funcional) para produzir significados (base semântica) em situações de comunicação".

Dessa forma, a língua passa de um simples sistema regulado por regras e toma proporções sociossemióticas, considerando-a como um sistema de produção de significados. Esta, por conseguinte, alicerça-se na Linguística Sistêmico-Funcional (LSF) (Halliday e Hasan, 1989)(Eggins, 1994)(Thompson, 2003)(Martin e White, 2005).

Segundo Halliday e Matthiessen (2004), a partir da perspectiva da LSF a linguagem estabelece-se por meio de funções, as quais podem ser relacionadas à organização do contexto e têm a capacidade de gerar significados.

As três metafunções são: a) ideacionais - servem à representação da realidade; são usadas para construir o campo da ação social; b) interpessoais - servem à interação entre os participantes; são usadas para negociar as relações sociais; c) textuais - servem como instrumentação estrutural às outras duas; estruturam os significados ideacionais e interpessoais de forma coesa e coerente (Santos, 2014).

Kress e Van Leeuwen (2006) partem da LSF e formulam uma teoria que analisa o texto visual (imagético) à luz de uma perspectiva sociossemiótica. Eles entendem que as imagens se articulam em composições visuais também produzindo significados. De acordo com essa perspectiva, encontramos as metafunções:

Representacionais - imagens podem representar ações ou conceitos (Kress e Van Leeuwen, 2006). Para Hendges et al. (2013, p. 244 - 246), “[...] os elementos recebem o nome de estruturas narrativas e focam nas ações dos envolvidos animados". As ações se manifestam através de vetores e setas.

Interacionais - imagens desenham um ponto de vista para o leitor. Segundo Kress e Van Leeuwen (2006), imagens favorecem a criação de opinião do leitor por meio dos recursos disponíveis: a) contato visual - tem função de indagar ou interrogar o leitor; b) distanciamento - enquadramento e planos determinam o quanto os elementos se aproximam ou não; c) relação de poder - ângulos estabelecem relações de poder entre elementos da imagem.

Composicionais - as imagens se organizam em textos visuais e interagem em textos multimodais. De acordo com Santos (2010, p. 7 - 9), “[...] três sistemas estão relacionados com os aspectos do layout do texto". Significados composicionais envolvem categorias como valores informacionais: realizados por meio de posição relativa centro (elemento núcleo e com mais importância) e margem (elementos subordinados ao núcleo) compondo as estruturas dado/novo e ideal/real. Os elementos posicionados à esquerda da página são tidos como dado, e os elementos à direita são o novo. Entenda-se por dado quando já conhecido pelo leitor, marcado como início da leitura da mensagem. O novo é o espaço destinado à apresentação da informação inédita a ser discutida. Moldura expressa os tipos de conexões entre os elementos e saliência realiza-se pelos efeitos do tamanho, cores e localização no primeiro plano.

No estudo, destaca-se a metafunção composicional, pois seus elementos serviram de suporte para o desenvolvimento da versão do aplicativo pedagógico proposto.

\section{3. $O$ aplicativo The Maze: a word hunt}

A necessidade de confeccionar o The Maze: a word hunt surgiu ao levantar o estado da arte e identificar a lacuna existente quanto à análise de um aplicativo em RV à luz da semiótica.

Em seguida, serão apresentados os seguintes aspectos do aplicativo: a escolha do nome; objetivos e jogabilidade. 


\subsection{Nome do aplicativo}

A escolha do nome do aplicativo tem a ver com o conteúdo linguístico pretendido à prática do aplicativo: léxico e fonética. Pensou-se em um ambiente mítico, onde vários modos (linguagens) fossem inseridos, construindo um arcabouço multimodal em formato de caça-palavras. Partiu-se da escolha de um artefato que favorecesse a prática do campo lexical e da fonética padrão internacional, concomitante com o International Phonetic Alphabet (IPA).

3.2 Objetivo do jogo

Dar suporte à prática do léxico e da fonética em língua inglesa.

3.3 A jogabilidade

O jogador tem como ponto de partida a sua queda no labirinto (Figura 1). Durante o experimento, o jogador usa óculos de RV (razão de o leitor ter uma visão da interface como se vista de um binóculo; às vezes, sem foco, pela falta de óculos de RV).

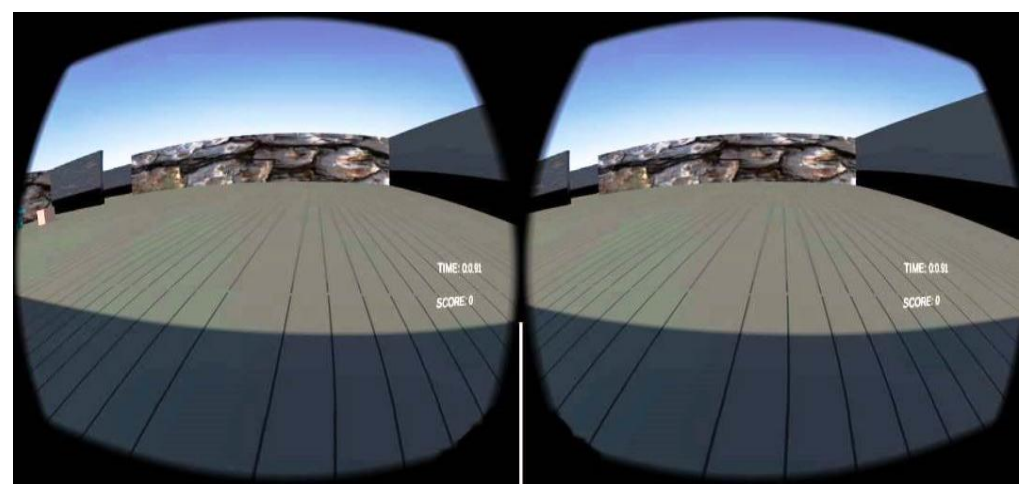

Figura 1 - Fase inicial do jogo

No início do jogo, ele se depara com caixas, as quais só revelam o conteúdo ao serem tocadas. Dentro delas encontram-se os campos lexicais divididos em dois grupos de palavras: a) even words (palavras alinhadas) - contribuem para o jogador identificar a keyword (palavra-chave) ou domínio (as even words são as que unem o campo lexical ao domínio correto no jogo); b) odd words (palavras desemparelhadas) - não favorecem a identificação de um campo lexical a um domínio. A Figura 1 traz a fase inicial do jogo. Na Figura 2, depara-se com um campo lexical contendo odd words, as quais não favorecem o jogador em seu objetivo.

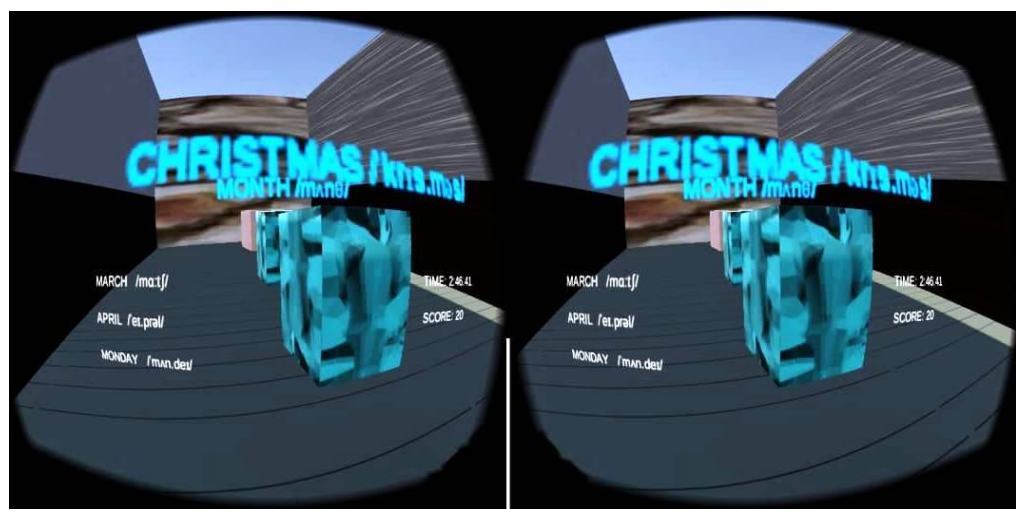

Figura 2 - Campo lexical contendo odd words

$\mathrm{Na}$ Figura 2, o campo lexical composto por March (março), April (abril) e Monday (segunda-feira) não corresponde ao domínio ou keyword Christmas (Natal), V. $19 \mathrm{~N}^{\mathrm{o}} 1$, julho, 2021 RENOTE 
tampouco ao domínio month (mês). Na Figura 3, o campo lexical Holiday (feriado), celebration (celebração) e Christian (cristã) corresponde ao domínio Christmas.

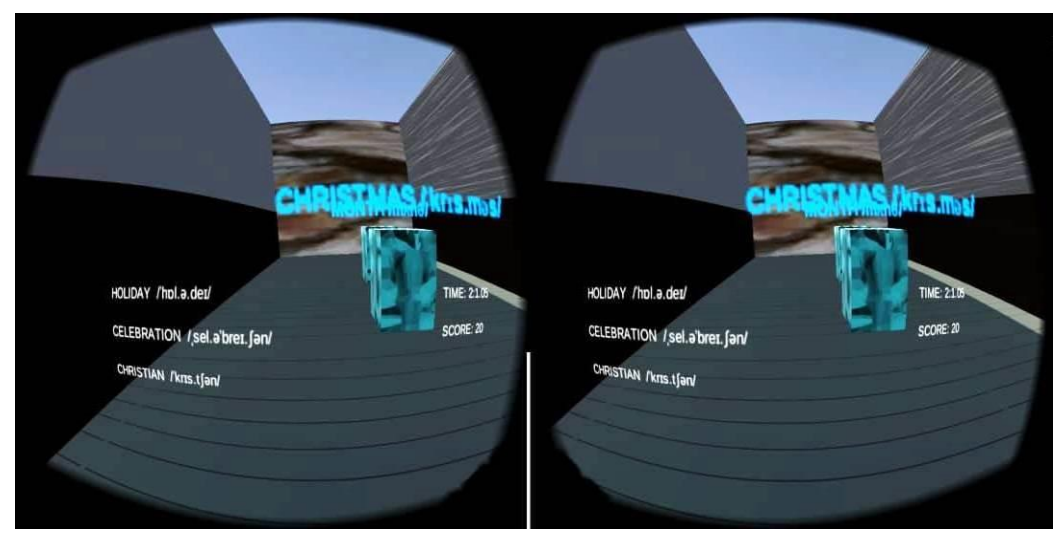

Figura 3 - Campo lexical contendo even words e seu respectivo domínio

\section{Métodos}

4.1 População do estudo

O estudo contou com 12 estudantes universitários, os quais cursavam a disciplina Língua Inglesa Instrumental I no curso de Filosofia da Universidade Católica de Pernambuco.

4.2 Coleta de dados

As sessões de uso do aplicativo foram realizadas na sala de aula, na Universidade Católica de Pernambuco, da disciplina Língua Inglesa Instrumental I. As sessões (em torno de seis minutos para cada aluno) foram realizadas no horário de aula da disciplina (1 dia, 2 aulas geminadas), contemplando doze alunos. $\mathrm{O}$ estudante acessou um link para instalação do aplicativo. O objetivo do estudante, no jogo, é avançar de fases, colecionando os badges (emblemas) que marcam o seu progresso no jogo. $\mathrm{O}$ avanço de fases depende de acertos no campo de vocabulário.

Duas cadeiras giratórias com braços de apoio foram utilizadas e os alunos foram acomodados devidamente sentados, posição em que ficaram durante todo o tempo da prática. $\mathrm{O}$ fato de encontrarem-se sentados evitou quaisquer tonturas ou desequilíbrios que pudessem eventualmente ser causados pelos óculos de Realidade Virtual.

Duas versões foram apresentadas no aplicativo. Versão A: considerando os recursos semióticos selecionados em conformidade com a Análise Composicional (AC) da Gramática do Design Visual (GDV). Versão B: não levando em consideração os recursos semióticos selecionados em conformidade com a AC da GDV. Logo após, cada aluno participou de uma pesquisa por meio do GoogleForms, na qual manifestou sua preferência por uma das versões apontando os dados que o levaram às escolhas.

Para declarar a preferência, o participante se deparou com figuras que $o$ remeteram a momentos do jogo. As perguntas foram voltadas a um determinado recurso semiótico utilizado na composição das interfaces do jogo.

\section{Análise e discussão}

Quando se pediu para os envolvidos levarem em consideração os objetivos do jogo e, logo depois, identificarem a opção que apresentava maior possibilidade de aprendizagem, a imagem representada na Figura 4 foi apontada por 83,3\% dos envolvidos. A interface apontada traz recursos de áudio, transcrição fonética, informações composicionais relativas ao núcleo (que põe o usuário em posição privilegiada em comparação a outros elementos), assim como a posição escolhida para o score (pontuação) do jogo, badge (emblema) e tempo de jogo. 
Comentários dos envolvidos: "Existem mais possibilidades [...] mesmo as letrinhas que têm nos dicionários de inglês".

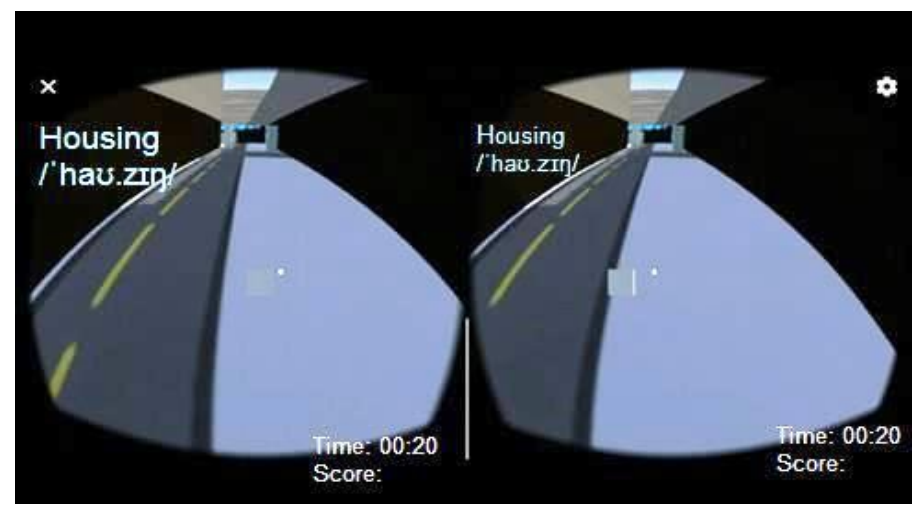

Figura 4 - Interface apontada com maior número de RS

O aluno faz alusão à transcrição fonética em dicionários. Sobre o comentário "mais possibilidades", entenda-se, segundo Santaella (2015, p. 6), uma referência aos diferentes modos e recursos usados, sejam eles: o próprio sistema de transcrição fonética, o som, as cores, a fonte, a sobreposição, entre outros, em conformidade com os valores composicionais da imagem - posição das informações e como se relacionam.

Nas Figuras 5 e 6, a valor informativo "e" leva o jogador à posição de núcleo. Valor que interage com todos os outros valores (significados representacionais). Os valores informativo e representacional de "e" o tornam superior a "c" e " $\mathrm{f}$ ", contudo, "e" precisa interagir com "c" e "f" (informativo inferior direito) para "e" manter-se motivado. O valor de "c" é real, o qual se refere à informação mais detalhada, mais empolgante (Kress e Van Leeuwen, 2001, p. 85 - 87)(Santos, 2010, p. 5 - 12), fato usual à gamificação (Ašeriškis et al., 2017).

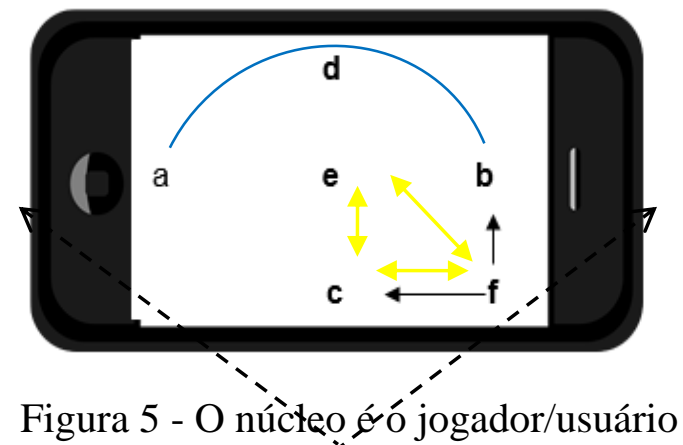

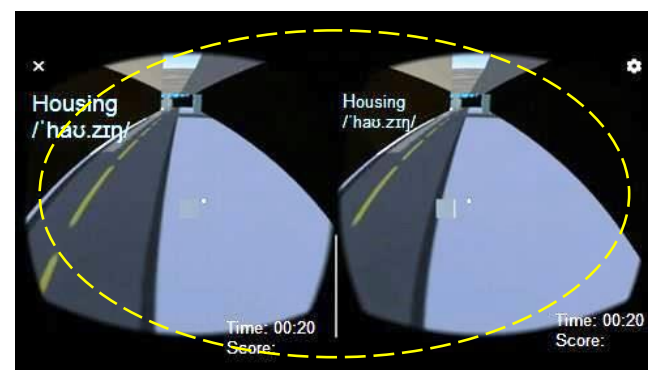

Figura 6 - A visão do núcleo

O modelo de análise baseado em Kress e Van Leeuwen (2006) e considerado por Santos (2010), Araújo (2012), Hendges et al. (2013) e Tavares (2020) deixa-nos claro que o valor da informação estabelece o lugar dos elementos. Araújo (2012) faz referência aos termos como participantes, sintagmas, que ora se relacionam entre si ora com quem os lê. Para Hendges et al. (2013, p. 242) "o léxico das imagens tem o poder de representar personagens": objetos, pessoas, fenômenos entre outros. Enquanto na linguagem verbal o léxico se realiza através de palavras, nas imagens ele equivale aos diferentes volumes, formas e localizações. Se à direita ou à esquerda, no alto ou embaixo, no centro ou na margem (Novellino, 2006).

No teste de preferência, foram apresentadas duas versões do mesmo ambiente, em interfaces diferentes. A opção 1 com o brilho a $20 \%$ e a opção 2 com brilho a $90 \%$. Observe as Figuras 7 e 8 respectivamente. 
Após o experimento, os envolvidos receberam a seguinte questão: Tomando como parâmetro um jogo com duração aproximada de seis minutos, em que o jogador deve além de manter-se com os óculos de RV, ter atenção para não perder nenhuma nova palavra, qual interface apresenta maior probabilidade de gerar fadiga $\mathrm{e}$ irritabilidade? Quase 60\% dos envolvidos responderam opção 1.

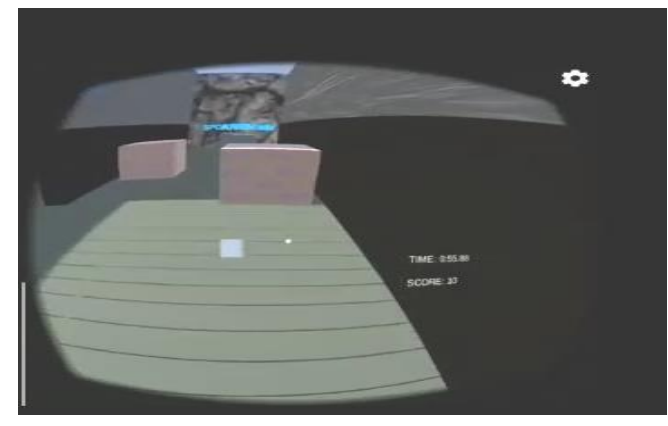

Figura 7 - Fluxo luminoso a 20\%

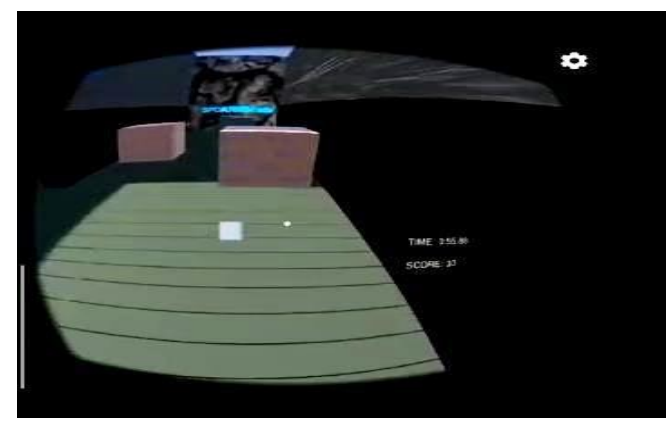

Figura 8 - Fluxo luminoso a 90\%

Quando os envolvidos foram indagados sobre a utilização da Realidade Virtual (RV) como favorecimento ao engajamento, houve quase total unanimidade entre os envolvidos no experimento (mais de $90 \%$ apontaram a RV como fator de engajamento, diversão e motivação). Crê-se importante pontuar que na Figura 9 vê-se a interface distorcida, pois para sua nitidez seria necessário o uso dos óculos de RV.

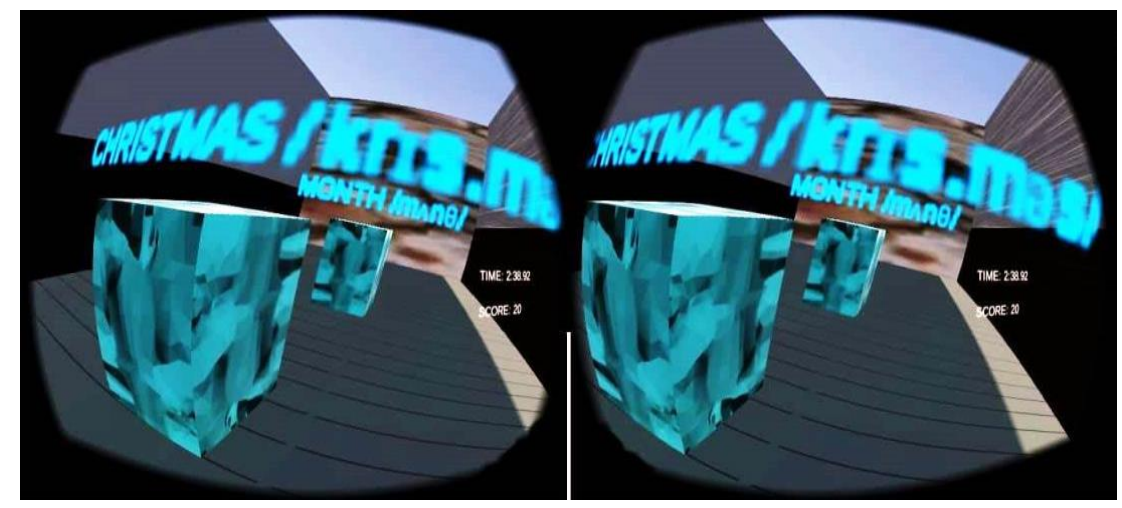

Figura 9 - Interface captada através dos óculos de RV

Os recursos semióticos sonoros, a música de fundo do The Maze e a fonética foram apontados por $75 \%$ dos participantes como engajadores e motivadores. Consideram-se justificativas como: "jogos devem ter som, música"; "Se é uma competição, a música dá gana e motiva"; "[...] poderia ser feito sem música, mas ela motiva para seguir".

Sendo a prática da fonética um dos objetivos do jogo, o sistema para transcrição fonética de novas palavras foi apontado como um dos recursos semióticos mais importantes no aplicativo.

Quando os participantes foram perguntados: Para o objetivo do jogo, você considera a transcrição fonética, como em castle (castelo) /'ka: $\mathrm{s}^{\curvearrowright} \mathrm{l} /$ ou poetry (poesia) /'pəひ·I.tri/ (Figura 10), um fator favorável ao processo de aprendizagem? Também $75 \%$ dos participantes responderam que "sim". Ainda segundo um envolvido: "a transcrição fonética e a repetição da nova palavra são essenciais para atingir o objetivo do jogo". 


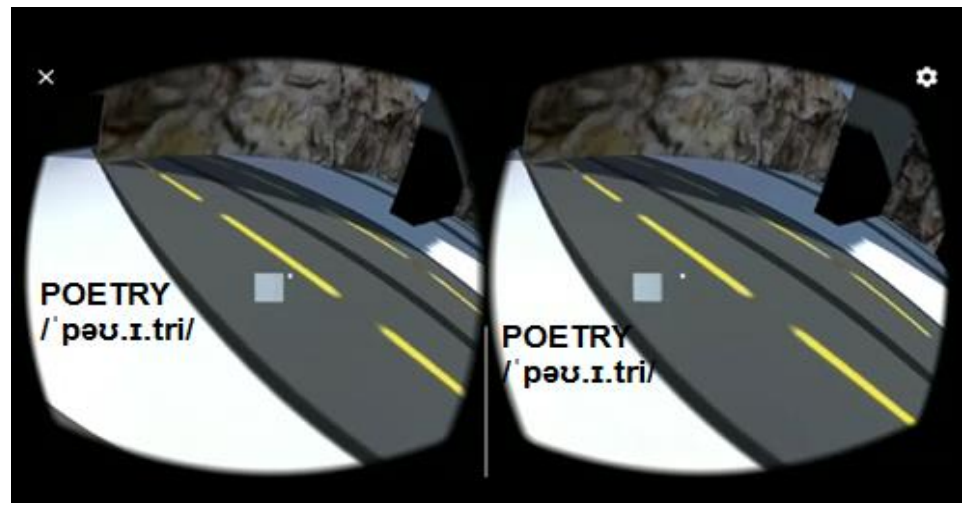

Figura 10 - Interface do aplicativo com transcrição /'pəひ· I·tri/

Durante o teste de preferência, os envolvidos ratificaram os valores informativos como recursos semióticos engajadores e motivadores de acordo com a GDV. Eles foram indagados sobre as semioses que compõem a interface (Figura 11): em qual ponto, A, B ou C, eles se sentiriam motivados a procurar palavras novas ou essenciais à aprendizagem?

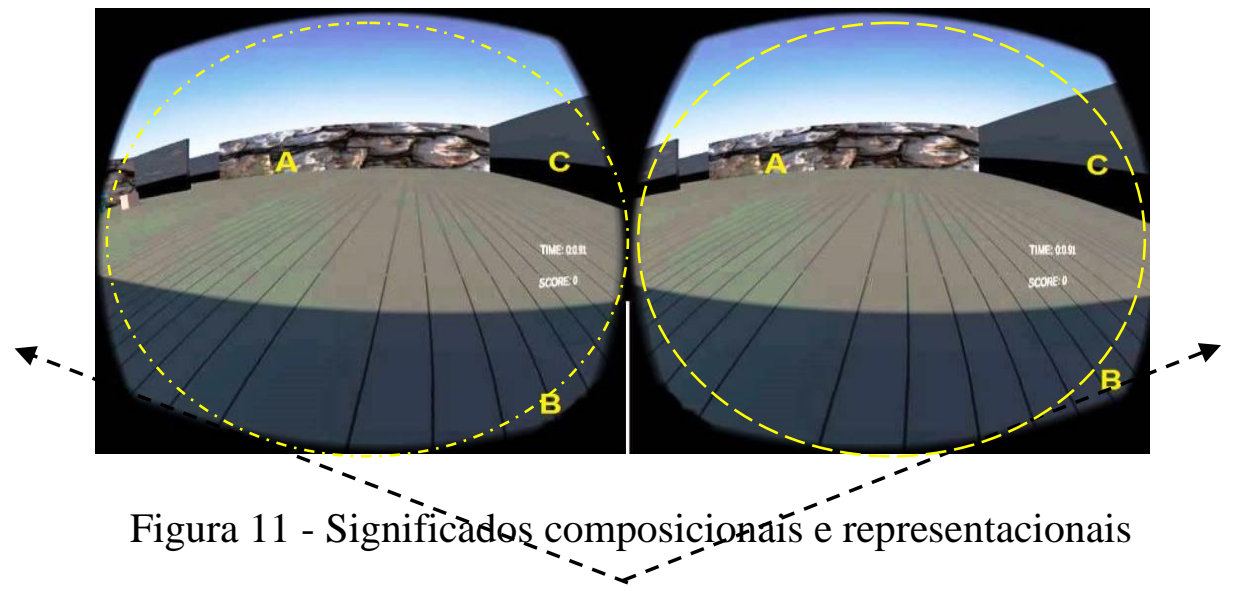

Em consonância com a GDV, em especial com a AC da imagem, ou seja, o modo como as imagens se organizam em textos visuais e interagem em textos multimodais por meio dos valores criados pela relação entre as semioses, logo gera nova significação (Kress e Van Leeuwen, 2006), os participantes do experimento ficaram (em maior número) entre as opções A $(58,4 \%)$ e C $(33,3 \%)$, respectivamente, núcleo e novo. $\mathrm{O}$ núcleo representa o valor centralizado e com ele interagem os valores subordinados como o novo, o qual se posiciona à direita da interface e carrega valores ainda não conhecidos ao usuário/jogador, o qual tem visão centralizada da interface.

\section{Considerações finais}

Os resultados obtidos neste estudo ratificam a Gramática do Design Visual (GDV) como ferramenta essencial ao estudo e análise da imagem, seja inerte ou em movimento. Os aportes descritivos da Análise Composicional (AC) permitem que os recursos dispersos nas imagens gerem sentidos e significação através de relações de valores.

Dentre os recursos semióticos considerados, destacam-se: ângulo, linhas, fundos neutros, disposição espacial, som, transcrição fonética, recursos verbais, brilho e luminosidade. 
Por meio do teste de preferência, os envolvidos destacaram como recursos semióticos intensificadores do interesse, motivação e engajamento da aprendizagem de inglês através do aplicativo The Maze: a) uso de música e sons. O The Maze usou sons para marcar o acerto e mudança de fases; b) em atividades envolvendo léxico e fonética, faz-se importante o uso da transcrição fonética; c) uso de elementos de gamificação, pois geram estímulos; d) cores quentes e frias, brilho e tons; e) uso da realidade virtual; f) valores informacionais da $\mathrm{AC}$, uma vez que estabelecem o "lugar dos elementos"; g) uso do texto verbal, pois facilita entendimento e cria possibilidades claras de significação.

A versão do aplicativo proposto fez uso de RV e contemplou recursos semióticos em sua composição. Foi uma ferramenta tecnológica significativa para uma aprendizagem mais engajada no ensino do léxico e da fonética da língua inglesa.

\section{Referências Bibliográficas}

ARAÚJO, J. Buddypokes: cenas multimodais de violência no Orkut. Antares, v. 4, p. $178-190,2012$.

ARAÚJO, S. S.; PARENTE, L. O.; ARAÚJO, A. D. A leitura da capa do livro Brincando de inventar na perspectiva da gramática do design visual. Revista Brasileira de Linguística Aplicada, v. 19, n. 3, p. 711-731, 2019.

AŠERIŠKIS, D.; DAMAŠEVIČIUS, R. Gamification patterns for gamification applications. Procedia Computer Science, v. 39, p. 83-90, 2014.

BEZEMER, J.; KRESS, G. Multimodality, learning and communication: A social semiotic frame. Routledge, 2016.

CAIADO, R. V. R.; DA FONTE, R. F. L.; BARROS, I. B. Textualidade em Tecnologia Digital Móvel: a construção da coesão e da coerência em textos imagéticos. Hipertextus, v. 19, p. $24-39,2018$.

DANIELSSON, K.; SELANDER, S. Reading multimodal texts for learning - a model for cultivating multimodal literacy. Designs for learning, v. 8, n. 1, p. 25 - 36, 2016

DONAGHY, K. Film in Action-Teaching language using moving images. Ernst Klett Sprachen GmbH, 2017.

EGGINS, S. An introduction to Systemic Functional Linguistics. 2. ed. London; New York: Continuum, 1994.

GOLDSTEIN, B. Visual literacy in English language teaching. Cambridge Papers in ELT series. Cambridge: Cambridge University Press. 2016.

GRIGOLETTO, E; DE NARDI, F. S.; SCHONS, C. R. Discursos em rede: práticas de (re)produção, movimentos de resistência e constituição de subjetividades no ciberespaço. Recife: Editora Universitária - UFPE, 2011.

GRUNDLINGH, L. Memes as speech acts. Social Semiotics, v. 28, p. 147-168, 2018. HALLIDAY, M. A. K. An introduction to functional grammar. London: LA, 1994. HALLIDAY, M. A. K.; HASAN, R. Language, context and text: aspects of language in a social-semiotic perspective. Oxford: Oxford University Press, 1989.

HALLIDAY, M.; MATTHIESSEN, C. An introduction to functional grammar. 3ed. London: Hodder Education, 2004.

HAMARI, J. Do badges increase user activity? A field experiment on the effects of gamification. Computers in Human Behavior, v. 71, p. 469-478, 2017.

HENDGES, G. R.; NASCIMENTO, R. G.; MARQUES, P. M. A Gramática da Imagem como Ferramenta na Análise Crítica de Gêneros Midiáticos. In: SEIXAS, L.; PINHEIRO, N. F. (Orgs.) Gêneros: um diálogo entre comunicação e linguística. Florianópolis: Insular. 2013. 
HERRERO, C.; VANDERSCHELDEN, I.; DONAGHY, K. Using film and media in the language classroom: reflections on research-led teaching. Multilingual Matters, 2019.

HODGE, B.; KRESS, G. Social semiotics. The Routledge Companion to Global Popular Culture. London: Routledge, 1988, 2014.

KRESS, G.; VAN LEEUWEN, T. Multimodal discourse: The modes and media of contemporary communication. London: Hodder Education, 2001.

KRESS, G.; VAN LEEUWEN, T. Reading and writing with images: a review of four texts. Reading Images: The Grammar of Visual Design. Computers and Composition, v. 1, n. 18, p. 85-87, 2001.

KRESS, G. Multimodality: A social semiotic approach to contemporary communication. London: Routledge, 2010.

KRESS, G.; VAN LEEUWEN, T. Reading Images. The Grammar of Visual Design. London: Routledge, 2006.

LIM, F.; V.; PHUA, J. Teaching Writing with Language Feedback Technology. Computers and Composition, v. 54, p. 102518, 2019.

MACENA, J. D.; DE ARAÚJO, A. A.; DOS SANTOS, J. S. Evaluation of the Use of Leaderboards in a Gamified Application for Academic Learning. RENOTE, v. 18, n. 2, p. 1-10, 2020.

MARTIN, J. M.; WHITE, P. The language of evaluation: appraisal in English. New York: Palgrave, 2005.

NOVELLINO, M. O. Gramática Sistêmico-Funcional e o estudo de imagens em livro didático de inglês como língua estrangeira. In: International Systemic Functional Congress, XXXIII, São Paulo: Proceedings, São Paulo: LAEL-PUC-SP. 2006. P. 315 330.

SANTAELLA, L. O que é semiótica - São Paulo: Brasiliense, 2015.

SANTAELLA, L.; NÖTH, W. Imagem. Semiótica, Mídia. SP: Iluminuras, 2015.

SANTOS, Z. B. As considerações da Gramática do Design Visual para a constituição de textos multimodais. 2010.

SANTOS, Z. B. A linguística sistêmico-funcional: algumas considerações. SOLETRAS, n. 28, p. 164-181, 2014.

SOUSA, M. A. A.; PINHEIRO, M. S. A construção de significados do infográfico Panorama das favelas em Fortaleza à luz da Gramática do Design Visual. Revista Brasileira de Linguística Aplicada, v. 19, p. 239 - 248, 2019.

TAVARES, E. L. C. A Linguagem dos Aplicativos à Luz da Semiótica na Aprendizagem Ubíqua em Aulas de Inglês. No estado de Pernambuco. Recife. PPGCL/Unicap, 2020. 166p. Tese de Doutorado.

THOMPSON, G. Introducing Functional Grammar. 2ed. Oxford: Univ. Press, 2003.

TRAXLER, J. Learning With Mobiles or "Mobile Learning" (in) LING, R.; FORTUNATI, L.; GOGGIN, G.; LIM, S. S.; Li, Y. (Eds.) The Oxford Handbook of Mobile Communication and Society. Oxford. Oxford University Press, 2020.

VON WANGENHEIM, C. G.; HAUCK, J. C.; PACHECO, F. S.; BUENO, M. F. B. Ferramentas Visuais para o Ensino de Machine Learning na Educação Básica. RENOTE, v. 18, n. 2, p. 511-520, 2020.

WIGHAM, C.; SATAR, H. M. A Multimodal Analysis of Task Instructions for Webconferencing-supported L2 Interactions. Ljubljana: Ljubljana Press, 2016.

ZHANG, Y.; O'HALLORAN, K. L. Empowering the point: Pains and gains of a writer's traversals between print-based writing and multimodal composing. Linguistics and Education, v. 51, p. 1-11, 2019. 